\title{
Arthroscopic Trapeziectomy and Suture Button Suspensionplasty: A Review of the Literature and Description of the "Three-Step Arthroscopic Trapeziectomy Technique"
}

\author{
Fernando Corella, $\mathrm{PhD}^{1,2,3}$ Montserrat Ocampos, $\mathrm{PhD}^{1,2}$ Rafael Laredo, MD²,4,5 \\ José Tabuenca, MD ${ }^{6}$ Maribel Carnicer, MD ${ }^{1}$ Ricardo Larrainzar-Garijo, PhD ${ }^{1,3}$
}

${ }^{1}$ Department of Orthopedic and Trauma, Hospital Universitario

Infanta Leonor, Madrid, Spain

${ }^{2}$ Hand Surgery Unit, Hospital Universitario Quironsalud Madrid, Madrid, Spain

${ }^{3}$ Department of Surgery, School of Medicine, Universidad Complutense de Madrid, Madrid, Spain

${ }^{4}$ Hand Surgery Unit, Department of Orthopedic and Trauma, Virgen de la Salud University Hospital, Madrid, Spain

${ }^{5}$ Department of Orthopedic and Trauma, Quironsalud Toledo, Toledo,

Spain

${ }^{6}$ Department of Orthopedic and Trauma, Hospital Universitario

Quironsalud Madrid, Madrid, Spain
Address for correspondence Fernando Corella Montoya, PhD, Department of Orthopedic and Trauma, Hospital Universitario Infanta Leonor, C/ gran vía del este $n^{\circ} 80$, Madrid 28031, Spain (e-mail: fernando.corella@gmail.com).

J Wrist Surg 2020;9:366-381.

\author{
Abstract \\ Keywords \\ - arthroscopic \\ trapeziectomy \\ - thumb \\ - suture button \\ suspensionplasty \\ - thumb osteoarthritis
}

In the last two decades, surgeons have rapidly developed arthroscopic techniques to treat basal joint osteoarthritis. Such techniques spare the joint capsule and ligaments, allow more accurate staging of cartilage degeneration to determine the most appropriate treatment, and decrease the risk of injury to the radial artery and superficial branch of the radial nerve. Arthroscopic resection arthroplasty of the trapezium can be performed as either partial or complete trapeziectomy. Many papers have described partial trapeziectomy but few have discussed complete trapeziectomy. Suture button implants avoid the drawbacks of temporary fixation using Kirschner wire, as well as the drawbacks of ligament reconstruction, which necessitates the sacrifice of a tendon and involves both wide exposure and scar tissue. This paper aimed to review the published data on the arthroscopic treatment of basal thumb osteoarthritis, with a special focus on stabilization using suture button suspensionplasty, and to present a technique that structures this procedure into three steps, allowing it to be performed in an easier, more organized, and faster way.
In the last two decades, surgeons have rapidly developed arthroscopic techniques to treat basal joint osteoarthritis. Such techniques spare the joint capsule and ligaments, allow more accurate staging of cartilage degeneration to determine the most appropriate treatment, and decrease the risk of

received

February 15, 2020

accepted

April 13, 2020

published online

July 30,2020 injury to the radial artery and the superficial branch of the radial nerve. ${ }^{1-3}$

Arthroscopic resection arthroplasty of the trapezium can be performed as either partial or complete trapeziectomy. The former is indicated in stage II or III cases, according to the

Copyright $\odot 2020$ by Thieme Medical Publishers, Inc., 333 Seventh Avenue, New York, NY 10001, USA.

DOI https://doi.org/ 10.1055/s-0040-1710560. ISSN 2163-3916. 
Eaton classification, ${ }^{4}$ whereas the latter can also be performed in stage IV cases. Many papers have described partial trapeziectomy, ${ }^{5-16}$ but few have discussed complete trapeziectomy. ${ }^{17,18}$

Numerous open surgery techniques, such as temporary Kirschner wire fixation, ${ }^{19}$ soft tissue interpositions, ${ }^{20}$ ligament reconstruction with or without tendon interposition, ${ }^{21}$ and, more recently, suture button suspensionplasty (SBS), ${ }^{22}$ have been developed to prevent proximal migration of the first metacarpal bone once the trapezium is removed. SBS was first performed using the Mini TightRope (Arthrex, Naples, FL), which maintains the height of the first metacarpal bone by fixing it to the second metacarpal bone using two stainless steel plates joined by two strands of $2 / 0$ FiberWire (Arthrex). ${ }^{23}$ Nowadays, other companies are developing suture button implants such as the MicroLink (Conmed, New York, NY).

Suture button implants avoid the drawbacks of temporary fixation using Kirschner wire, which is necessary when using the hematoma and distraction arthroplasty technique and involves a long period of immobilization (4-6 weeks) as well as an infection risk at the pin site. ${ }^{24,25}$ Similarly, SBS avoids the drawbacks of ligament reconstruction, which necessitates the sacrifice of a tendon and involves both wide exposure and scar tissue formation to obtain the graft and for its fixation.

First, this study aims to review the published data on the arthroscopic treatment of basal thumb osteoarthritis, with a special focus on stabilization using SBS. Second, because few papers have described complete arthroscopic trapeziectomy in detail, this study aims to present a technique that structures this procedure into three steps, allowing it to be performed in an easier, more organized, and faster way.

\section{Arthroscopic Partial Trapeziectomy}

Arthroscopic partial trapeziectomy is a good option in young patients if the cartilage in the proximal surface of the trapezium is preserved to maintain thumb length. Partial trapeziectomy resects 3 to $4 \mathrm{~mm}$ of the distal surface of the trapezium. The space created can then be managed in three different ways. First, it can be filled using various interposition materials to avoid any new impingement between the first metacarpal and the proximal portion of the trapezium. Second, the surgeon can leave it empty, without introducing any kind of material or stabilizing the metacarpal. Finally, to avoid new collapse, the first metacarpal can be stabilized using SBS.

\section{Interposition Material}

Some surgeons prefer placing interposition material into the partial trapeziectomy space to preserve metacarpal height and prevent bony impingement. A variety of materials such as autograft, allograft, and prostheses have been used for this purpose. Among autografts, the donor options are the flexor carpi radialis (FCR) and palmaris longus tendons, ${ }^{3}$ although the fascia lata has also been used as an allograft. ${ }^{13}$ Prosthetic materials include the Artelon Spacer (Artimplant, Vastra Frolunda, Sweden) ${ }^{26}$ and GraftJacket (Wright Medical Technology, Arlington, TN). ${ }^{27}$
Menon ${ }^{13}$ was the first author to report an arthroscopic partial trapeziectomy in 1996. As an interposition material, he used an autogenous tendon graft, Gore-Tex, and a fascia lata allograft. In 24 to 48 months of follow-up, complete pain relief was shown in 25 patients.

Two more papers on this topic were published in 2007. The first was by Pegoli et $\mathrm{al}^{3}{ }^{3}$ who described their experience of 16 arthroscopic hemitrapeziectomies in which interposition was performed using the palmaris longus tendon. According to the Mayo score, the results were excellent in six patients, good in another six, fair in three and poor in one after 12 months of follow-up. The second paper was published by Adams et al, ${ }^{27}$ who reported the results of the procedure in 17 patients using the dermal matrix allograft GraftJacket (Wright Medical Group, Memphis, TN). All patients reported symptomatic pain relief and an improvement in one or more activities of daily living in an average of 17 months of follow-up.

One year later, Earp et $\mathrm{al}^{12}$ published the results of 15 arthroscopic partial trapeziectomies with tendon interposition. Their patients' visual analog scale score decreased from 8.6 to 1.8 after a mean follow-up period of 11 months, and they recorded a grip strength of $90 \%$, a lateral pinch of $85 \%$, and a key pinch of $90 \%$ compared with the contralateral side.

In 2008, Badia ${ }^{26}$ described arthroscopic partial trapeziectomy and interposition using the Artelon Spacer, reporting preliminary results in 13 thumbs of 12 patients. All patients had marked pain relief and slightly improved pinch strength compared with preoperative levels.

Four years later, Park et $\mathrm{al}^{28}$ published results using the Artelon Spacer. At a minimum of 1 year of follow-up, the patients' Disabilities of the Quick Arm, Shoulder and Hand Score (QuickDASH) and patient-rated wrist evaluation scores were 12.3 and 26.8, respectively. Only one patient developed persistent synovitis 3 months after the procedure, which was resolved using one corticosteroid injection.

Additionally, in 2012, Desmoineaux et $\mathrm{al}^{5}$ described a new arthroscopic technique, in which ligament reconstruction was performed using the abductor pollicis longus, which acted as both a suspension and an interposition material. They performed the procedure in 49 patients, with a mean follow-up period of 3.6 years. There was an improvement in both pinch and grip strength, opposition motion, and degree of first web opening. Furthermore, $83.5 \%$ of the patients were satisfied with the procedure, $96 \%$ of the thumbs were stable, and $74 \%$ were pain-free. There were four cases of radial nerve irritation and one of FCR tendinitis.

In 2015 , Chuang et $\mathrm{l}^{15}$ performed 23 arthroscopic partial trapeziectomies using the palmaris longus tendon. They reported improvement in pain score, range of motion, and pinch strength in spite of a proximal collapse of the first metacarpal bone of $2.1 \mathrm{~mm}$ at 24 months of follow-up.

More recently, in 2018, Logli et al ${ }^{11}$ reported the results of the procedure with a longer follow-up than previous studies (after 6 months and 5 years). As an interposition material, they used the dermal matrix allograft GraftJacket. Using the visual analog scale, pain decreased from 8.2 before surgery to 1.3 at the 6 -month follow-up and to 0.8 at the 5 -year follow-up. The 
QuickDASH scores significantly decreased from 17.5 to 8.9 between the 6 -month and 5 -year follow-ups. There was also a joint space collapse from 1.42 to $0.83 \mathrm{~mm}$. There were seven complications: five patients suffered transient superficial radial nerve neuritis, one developed a hyperextension deformity in the metacarpophalangeal joint requiring arthrodesis, and one developed a painful instability of the thumb metacarpal base but declined additional treatment.

\section{No Interposition Material}

Although many surgeons choose to place interposition material, some papers suggest that it may not be necessary to obtain a favorable outcome. Partial trapeziectomy combined with ligament reconstruction or capsular shrinkage has shown good results, even in the long term. ${ }^{6,7}$

In 2009, Hofmeister et $\mathrm{al}^{6}$ presented the results of this procedure in 18 patients undergoing arthroscopic partial trapeziectomy and thermal capsular shrinkage, with a follow-up period of more than 7 years. Using the thumb function score, an improvement from 60 to 90 was observed. Follow-up radiographs from the last visit showed a collapse of $1.8 \mathrm{~mm}$ of the first metacarpal. None of the patients required revision surgery. There were four complications: two cases of dorsal radial nerve neuritis, one of skin necrosis, and one of pain in the flexor pollicis longus.

In 2010, Edwards and Ramsey ${ }^{7}$ published a prospective study of 23 patients treated using arthroscopic hemitrapeziectomy and thermal capsular shrinkage without interposition, with 4 years of follow-up. After 12 weeks, there was an improvement in the DASH score (10 vs. 61 ), pain (1.5 vs. 8.3 ), and grip and pinch strength, as well as a collapse of $3 \mathrm{~mm}$ in the first metacarpal. After 4 years, these measures remained unchanged. Only one complication occurred: a painful neuroma due to pin placement.

Finally, Cobb et al ${ }^{1}$ compared subjective and objective outcomes between 73 cases without interposition and 52 cases using GraftJacket as an interposition material. The mean follow-up period was 6.5 years. They found no differences in the pain score or in grip and pinch strength. Final satisfaction was $4.7 / 10$ in the group with interposition and 4.4/10 in the group without interposition. There were four failures in the group with interposition and two in the group without. When comparing pain outcomes in the subgroup in which scaphotrapeziotrapezoidal (STT) joint resection was performed, no differences were found between the groups.

\section{Suture Button Suspensionplasty}

In recent years, hemitrapeziectomy using SBS has gained popularity. SBS techniques provide stability to the thumb comparable to that provided by ligament reconstruction or Kirschner wires fixation, but without the complications of those approaches.

The most common system of SBS is the Arthrex Mini TightRope, which comprises two strands of ultrahigh molecular weight suture polyethylene and polyester braided over a core of the same material, with two stainless steel buttons for cortical fixation. Previous studies have reported that Tight-
Rope fixation provides stability after orthopedic surgery in several areas such as the shoulder, foot, and ankle. ${ }^{23}$

In a biomechanical study, Yao et $\mathrm{al}^{29}$ demonstrated that SBS provides mechanical resistance against collapse comparable to that provided by percutaneous pins, with the added benefit of early postoperative mobilization. Other biomechanical studies have reported that SBS shows better resistance to collapse than ligament reconstruction and tendon interposition. ${ }^{30,31}$

In 2010, Cox et $\mathrm{al}^{8}$ were first ones to describe SBS in 16 patients undergoing arthroscopic hemitrapeziectomy, with encouraging results. Two years later, Yao and Song ${ }^{32}$ reported the results in 21 patients who underwent SBS after partial (arthroscopic) or complete (open) trapeziectomy. At an average follow-up period of 2.8 years, the patients' mean QuickDASH score was 10 , whereas their pinch and grip strength were 86 and $89 \%$ of those on the contralateral side, respectively. The average trapezial space height was $74 \%$ of the preoperative value. Two complications occurred in the same patient: chronic regional pain syndrome and a fracture of the second metacarpal bone. Index metacarpal fractures after SBS have been reported by other authors. Although the use of first-generation devices could explain these complications because such devices used a $2.7-\mathrm{mm}$ drill, $^{33,34}$ fracture of the same bone has been reported recently using the second-generation technique, which only requires a $1.0-\mathrm{mm}$ Kirschner wire. ${ }^{35}$

In 2016, Roman et $\mathrm{al}^{36}$ evaluated 18 patients who had undergone open complete trapeziectomy and SBS. Grip strength, key pinch, and thumb abduction showed an improvement after surgery. Additionally, all but one patient had complete pain relief. No proximal migration of the first metacarpal occurred between 6 weeks and 1 year of follow-up. There were two complications: one fracture of the second metacarpal and one patient with ongoing pain due to spurring of the ulnar base of the first metacarpal.

In 2017, Yao and Cheah $^{34}$ published the intermediate outcomes of SBS in 16 cases undergoing partial or complete trapeziectomy. The mean follow-up period was 64 months. The patients' QuickDASH score improved to 58.2, whereas their Kapandji scores were 9 or 10 and their pinch and grip strength were 107 and $102 \%$ of those on the contralateral side, respectively. There were three complications: two incidents of transient neurapraxia of the dorsal radial sensory radial nerve and one of pain over the plate that required secondary surgery.

Additionally, in 2017, Wong and $\mathrm{Ho}^{16}$ published the results of nine cases of partial trapeziectomy and SBS. Six of the patients showed improvements in rest pain, exertion pain, and pinch and grip strength at an average follow-up period of 9.3 months. There was one case of unsatisfactory results and two cases of fair results. In all three cases, inadequate resection of the osteophytes at the ulnar side of the trapezium was found.

At the time of this review, the latest study on hemitrapeziectomy and SBS was that published by Özçelik et $\mathrm{al}^{14}$ in 2019. They reported the results of the procedure in 21 patients. Pain score was decreased from 8.2 to 1.9 after 
50 months of follow-up. There was also an improvement in the DASH score and in grip and pinch strength. A 2-mm trapezial space was maintained throughout the follow-up.

\section{Arthroscopic Total Trapeziectomy}

In many open surgical techniques, the trapezium is resected completely in both stage III and stage IV cases. Such complete trapeziectomy can also be performed arthroscopically. To date, only two reports have described complete arthroscopic trapeziectomy. The first was published in 2003 by Daroda et al, ${ }^{17}$ who described complete arthroscopic trapeziectomy without any further stabilization. They reported the preliminary results in 15 patients. ${ }^{37}$ After surgery, there was an improvement in pain, with excellent or good results in $87 \%$ of cases. There was also an improvement in grip and pinch strength compared with the preoperative value. To date, these authors have performed more than 70 complete trapeziectomies. The most frequent complication found was transient neurapraxia of the radial nerve sensory branch or of a section of the extensor pollicis longus. One case of great hematoma in the palmar forearm also occurred, probably caused by a radial artery injury. The authors mentioned that they usually leave small bone fragments in the surrounding soft tissues.

Another study on arthroscopic total trapeziectomy was published by Landes et a ${ }^{18}$ in 2016. In their large series, an arthroscopic hemitrapeziectomy was performed in 97 cases and a complete trapeziectomy in 56 cases. All the resections were stabilized using SBS with the Mini TightRope. There was a slight improvement in pinch strength of the affected side compared with the unaffected side, and revision surgery was performed in less than $6 \%$ of cases after 58 weeks of follow-up. In three cases, a repositioning of the button on the index metacarpal was required. Five patients underwent an additional bone procedure (conversion of the hemitrapeziectomy to total trapeziectomy and resection of the ulnar osteophyte). Finally, one patient suffered osteomyelitis of the first and second metacarpal bones, and the suture button was removed 6 weeks after surgery.

\section{The Three-Step Arthroscopic Trapeziectomy Technique}

Preparation, Instruments, and Patient Positioning

The three-step arthroscopic trapeziectomy technique ( - Video $\mathbf{1}$ ) is performed under either regional (axillary block) or general anesthesia, with a pneumatic tourniquet placed at the upper arm, close to the armpit. The patient is placed in the supine position, with the affected arm on a hand table. The wrist is maintained in vertical traction during the whole procedure, even during suture button fixation. The traction tower commonly used is an Arc Wrist Tower (Acumed, Hillsboro, OR), which maintains vertical traction and leaves the volar side of the wrist free.

\section{Video 1}

The three-step arthroscopic trapeziectomy technique. Online content including video sequences viewable at: https://www.thieme-connect.com/products/ ejournals/html/10.1055/s-0040-1710560.

Because the trapeziometacarpal joint is so small, it is difficult to maintain the correct view, especially when part of the trapezium was been resected and the arthroscope cannot rest over the bone. Furthermore, in such a small space, it is easy to injure other bones with the burr, such as the base of the second metacarpal, trapezoid, or scaphoid, or even damage the scope itself. For this reason, it is important that the surgeon makes accurate movements with both the scope and the burr. To do so, one surgeon must act as the cameraman, holding the scope with both hands to maintain a perfect view, while the other surgeon resects the bone, holding the hand piece in both hands. To ensure that two surgeons can work at the same time, there are two possible positions (-Fig. 1). The first involves

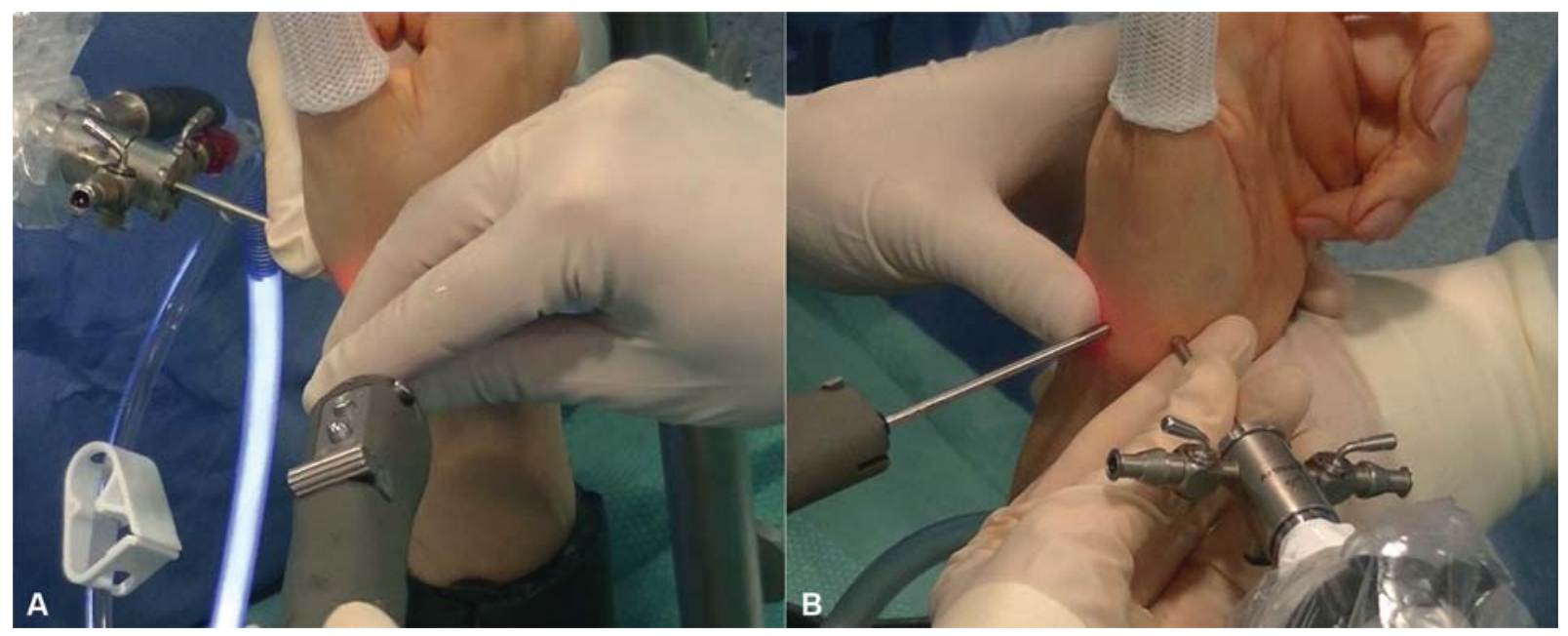

Fig. 1 To ensure that two surgeons can work at the same time, there are two possible positions. (A) The first involves one surgeon working on the dorsal side, with the other surgeon on the volar side. (B) The second option has both surgeons working on the dorsal side, with the patient's hand in a supinated position. 
one surgeon working on the dorsal side, with the other surgeon on the volar side. Although this is the most comfortable position, one surgeon must work with an inverted view in the screen. The second option has both surgeons working on the dorsal side, with the patient's hand in a supinated position. This way, the view is normal, but the surgeons are very close one to on another, making the procedure less comfortable.

To check the amount of bone resection and to place the suture button, a fluoroscope is used. With a sterilized dressing completely covering the C-arm, the fluoroscope enters parallel to the floor from the volar side of the wrist. This way, a fluoroscopic view can be obtained without releasing traction or losing sterility.

Arthroscopic shavers and burrs for small joints are used throughout the procedure (3- or 3.5- $\mathrm{mm}$ shaver and 3-mm burr). To remove the bone faster, three more instruments may be useful: (1) a 4-mm burr (7-cm in length, which is easier to use in the wrist), (2) a periosteal elevator, which is commonly used in percutaneous foot surgery to facilitate the separation of bone from the capsule and ligament attachments, and (3) a pituitary rongeur, which allows large portions of the bone to be removed. Using these aids, the inner portion of the bone is removed using burrs; once only the peripheral portion is left, the periosteal elevator is used to separate the bone from the capsule. Finally, the bone is removed using the pituitary rongeur.

The setup of the portals, as well as the joint exploration, is performed without a saline infusion using the arthroscopy dry technique popularized by del Piñal. ${ }^{38}$ During the rest of the procedure, saline infusion is only used to aspirate all the bone debris.

\section{Indications}

Complete trapeziectomy is indicated in stage IV of the Eaton classification, ${ }^{39}$ as well as in stage III, as it is commonly performed as part of open techniques that completely resect the trapezium.

In our own practice, we perform hemitrapeziectomy in young patients (normally under 60 years) at stage III to maintain ligament attachment. In such patients, even when $\mathrm{X}$-ray is normal, we always check the STT joint from the radial midcarpal portal. If the joint has degenerative changes, the indication is changed to complete trapeziectomy.

In older patients at stage III, especially those with advanced degenerative changes in the base of the first metacarpal bone, great subluxation, or large ulnar osteophyte, we prefer complete, direct bone resection to avoid the possibility of repeat surgery to correct collapse of the first metacarpal bone or painful impingement of the remaining trapezium.

\section{Surgical Technique}

To ensure faster, safer, and organized arthroscopic resection, we have developed the three-step arthroscopic trapeziectomy technique, which involves the structured resection of three different portions (zones) of the trapezium (-Fig. 2). Zone 1 is the biggest portion, covering twothirds of the trapezial ulnar side but not the cartilage or subchondral bone over the scaphoid. Zone 2 is the half volar bone covering one-third of the trapezial radial side, as well as the cartilage and subchondral bone over the scaphoid. Zone 3 is the rest of the bone, specifically the dorsal half of the bone covering one-third of the radial side of the trapezium.

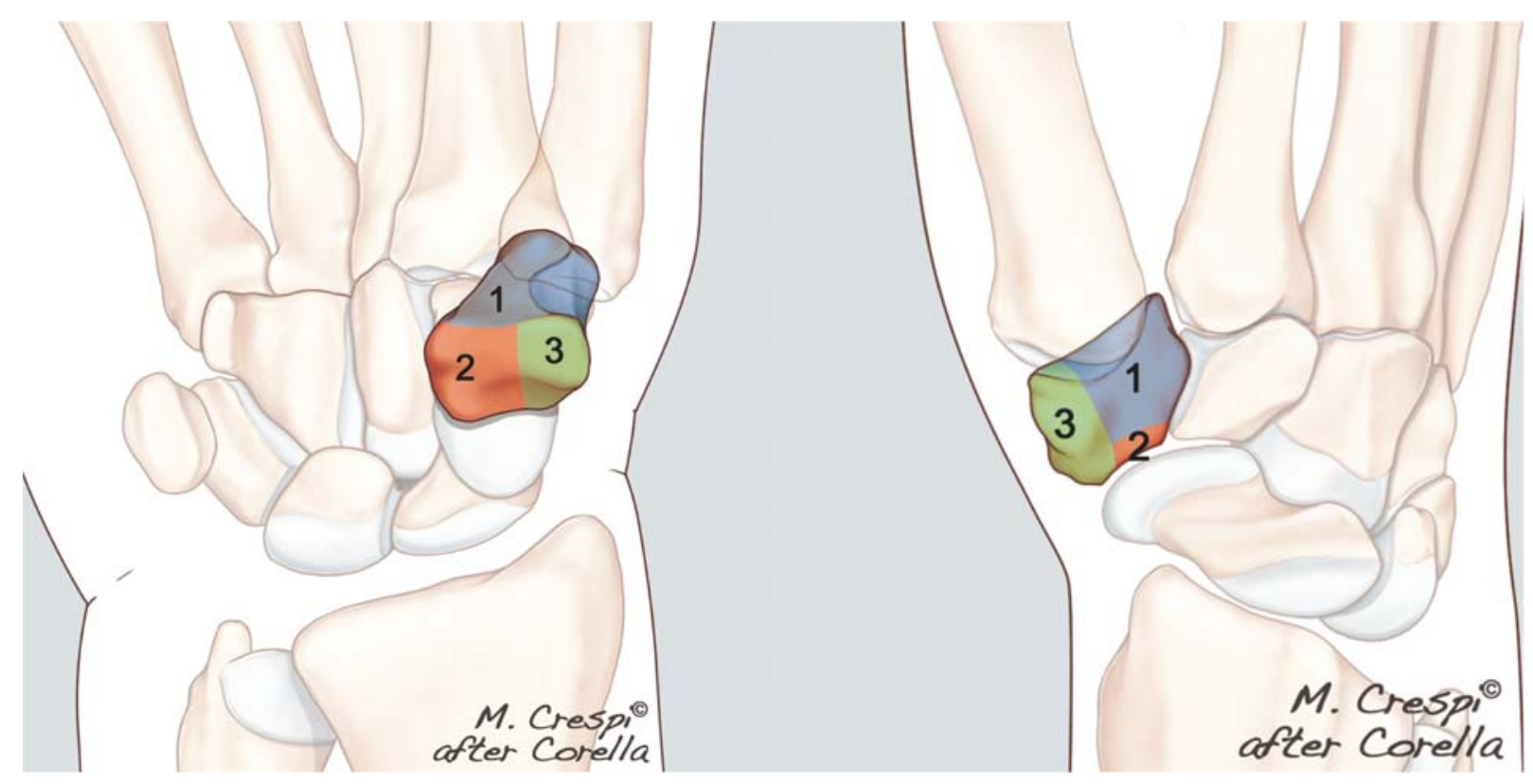

Fig. 2 The trapezium is divided into three different portions (zones). Zone 1 is the largest, covering two-thirds of the ulnar side of the trapezium but not the cartilage and subchondral bone over the scaphoid. Zone 2 is the half volar bone covering one-third of the radial side of the trapezium, as well as the cartilage and subchondral bone over the scaphoid. Zone 3 is the half dorsal bone covering one-third of the radial side of the trapezium. 


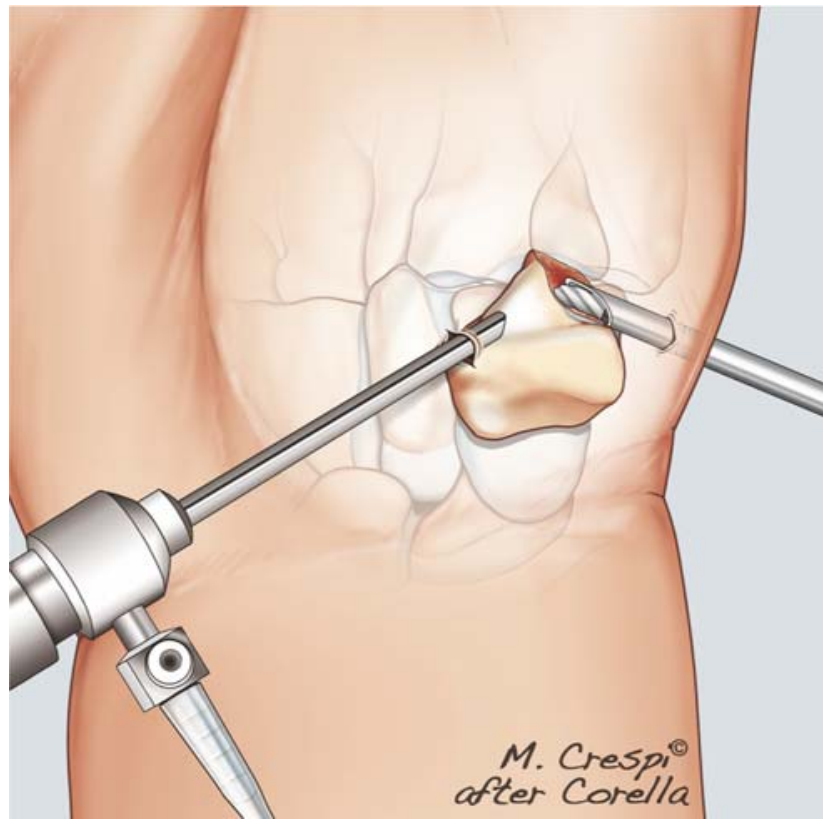

Fig. 3 Step 1. With the arthroscope in the thenar portal, the bone of zone 1 is removed.

\section{STEP 1: Zone 1 Resection}

The first portal, placed in the thumb carpometacarpal (CMC) joint, is the $1 \mathrm{U}$ portal. It is located ulnar to the extensor pollicis brevis tendon. A 22-gauge needle is introduced into the joint. If there is any doubt, the fluoroscope can be used to check the correct position of the portal. A 3-mm skin incision is made using a no. 11 blade, the soft tissues are dissected bluntly, and the capsule is penetrated using a blunt forceps. Finally, a 2.4-mm arthroscope is introduced into the joint.

The second portal placement is performed under arthroscopic control using the light source of the arthroscope. To this end, we use the thenar portal ${ }^{40,41}$ and not the $1 \mathrm{R}$ portal because the angle between the thenar and $1 \mathrm{U}$ portals is higher than 90 degrees, making manipulation of the instruments easier. The thenar eminence is illuminated, and a 22gauge needle is placed into the bulk of the thenar muscle at the level of the CMC joint.

Next, the arthroscope is moved from the $1 \mathrm{U}$ portal to the thenar portal to ensure that the ulnar portion of the trapezium, the second metacarpal bone, and the trapezoid are immediately in front of the arthroscope. In this first step, the bone of zone 1 is removed ( $\mathbf{F i g . 3}$ ).

A 3-mm burr is then inserted through the $1 \mathrm{U}$ portal, and the bone resection begins in the middle of the trapeziumimmediately in front of the portal. This small burr is only used to widen the $1 \mathrm{U}$ portal and allow the $4 \times 7 \mathrm{~cm}$ burr to be introduced. Using this larger burr, the inner portion of zone 1 is removed, leaving the cartilaginous and peripheral surface of the bone (-Fig. 4). During this step, the arthroscope rests over the radial portion of the trapezium (zones 2 and 3).

The first peripheral portion to be removed is the ulnar osteophyte, which can be very large in some cases. To facilitate its resection, the periosteal elevator is introduced through the $1 \mathrm{U}$ portal and used to horizontally cut the peripheral ulnar portion of the bone. This separates all the osteophyte from the proximal portion of the bone. The periosteal elevator is then used to reach the ulnar and distal portion of the osteophyte, which is detached from the capsule by applying downward pressure. Once the osteophyte has been mobilized, the pituitary rongeur is introduced and used to catch and remove it (-Fig. 5).

Finally, the rest of the inner portion of zone 1 is removed using the 4-mm burr, the periosteal elevator, and the rongeur, leaving only the proximal cartilage and subchondral bone in contact with the scaphoid (-Fig. 6).

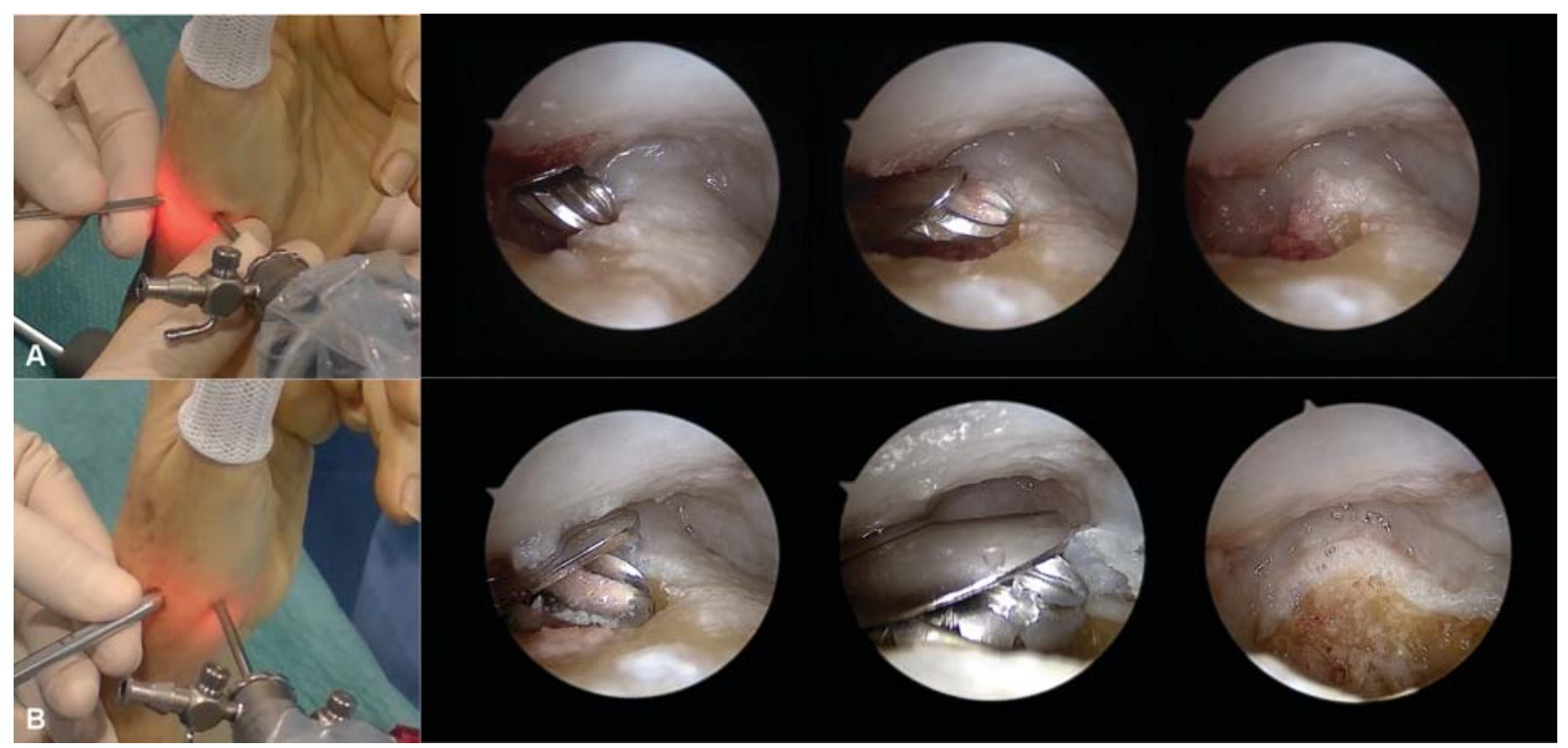

Fig. 4 (A) Initially, a 3-mm burr is introduced through the $1 \mathrm{U}$ portal and used to resect the bone enough to introduce the 4-mm burr. (B) Once there is enough space, the 4-mm burr is introduced and the inner portion of zone 1 is removed, leaving the cartilaginous and peripheral surface of the bone. 


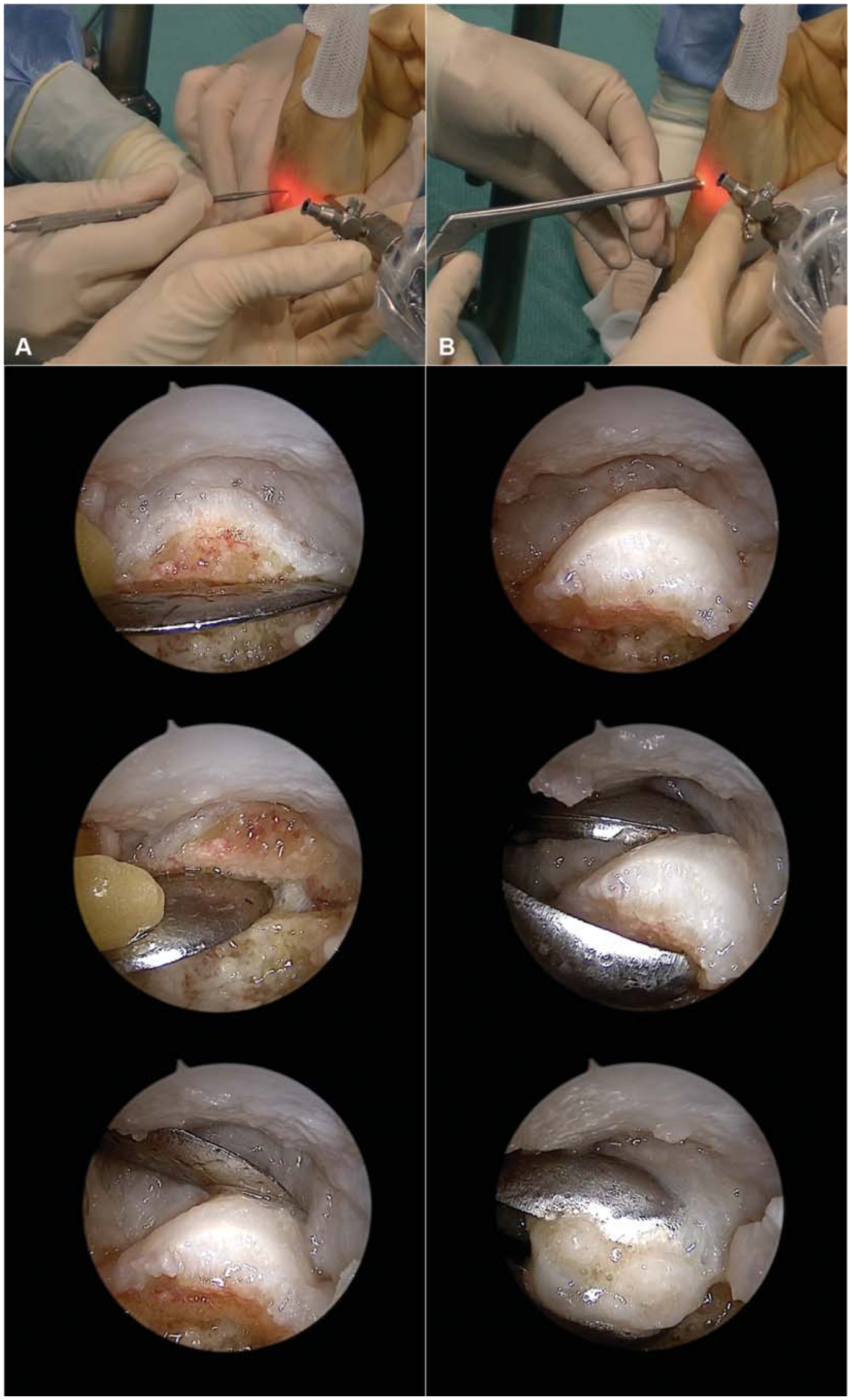

Fig. 5 Resection of the ulnar osteophyte. (A) Initially, a periosteal elevator is introduced through the 1 U portal and used to horizontally cut the peripheral ulnar portion of the bone. Once this is separated from the proximal portion of the bone, the periosteal elevator is used to reach the ulnar and distal portion of the osteophyte and detach it from the capsule. (B) Once the osteophyte is mobilized, a pituitary rongeur is introduced and used to catch and remove the osteophyte. 


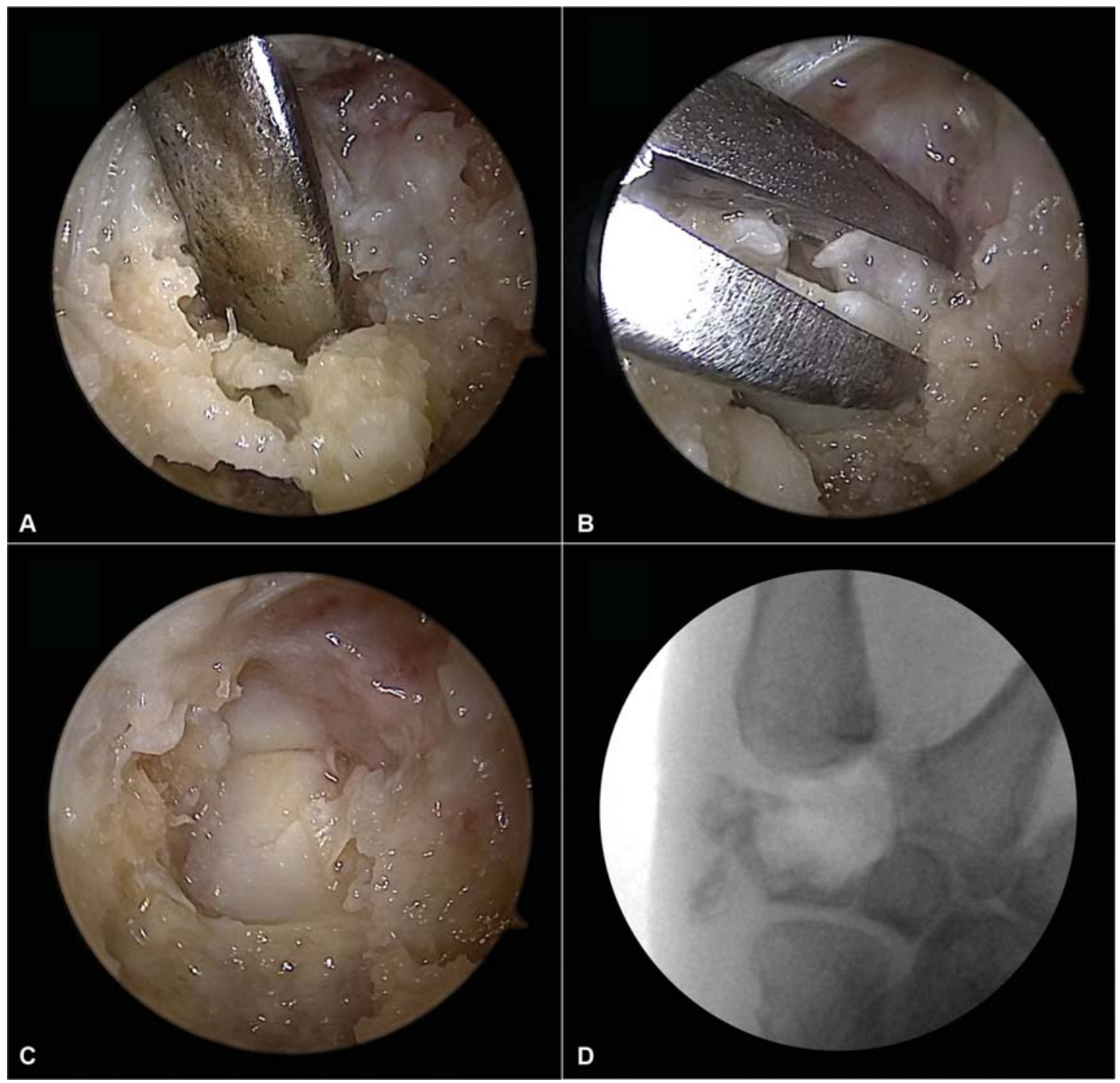

Fig. 6 Step 1 finishes removing the peripheral portion of the bone of zone 1 using the periosteal elevator and rongeur.

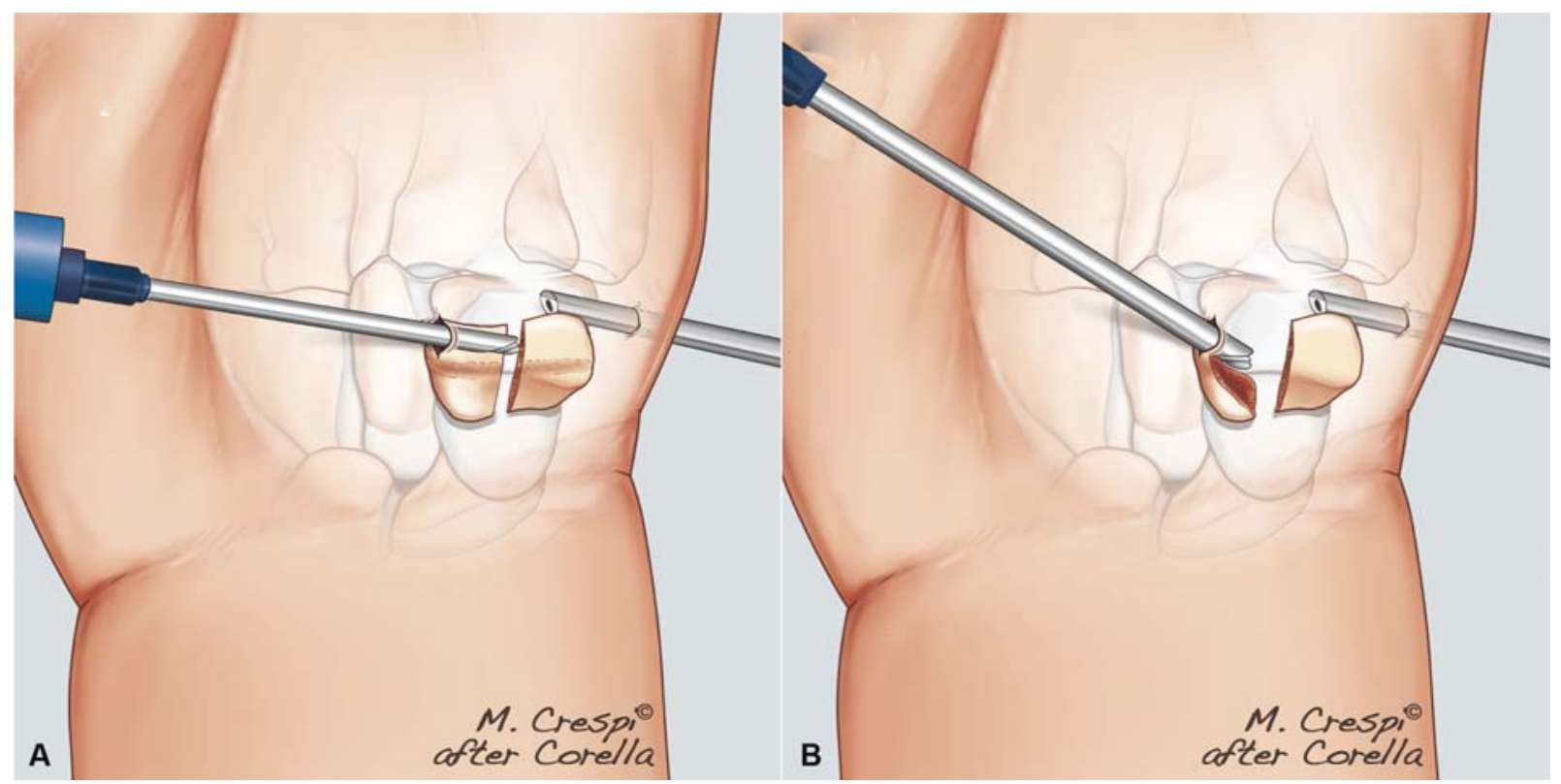

Fig. 7 (A) Step 2. This step begins by cutting and bisecting the radial portion (zones 2 and 3). (B) Once both the zones are separated, zone 2 is resected. In this step, the arthroscope is located in the $1 \mathrm{U}$ portal, resting over the proximal bone and cartilage of the trapezium, covering the scaphoid. 


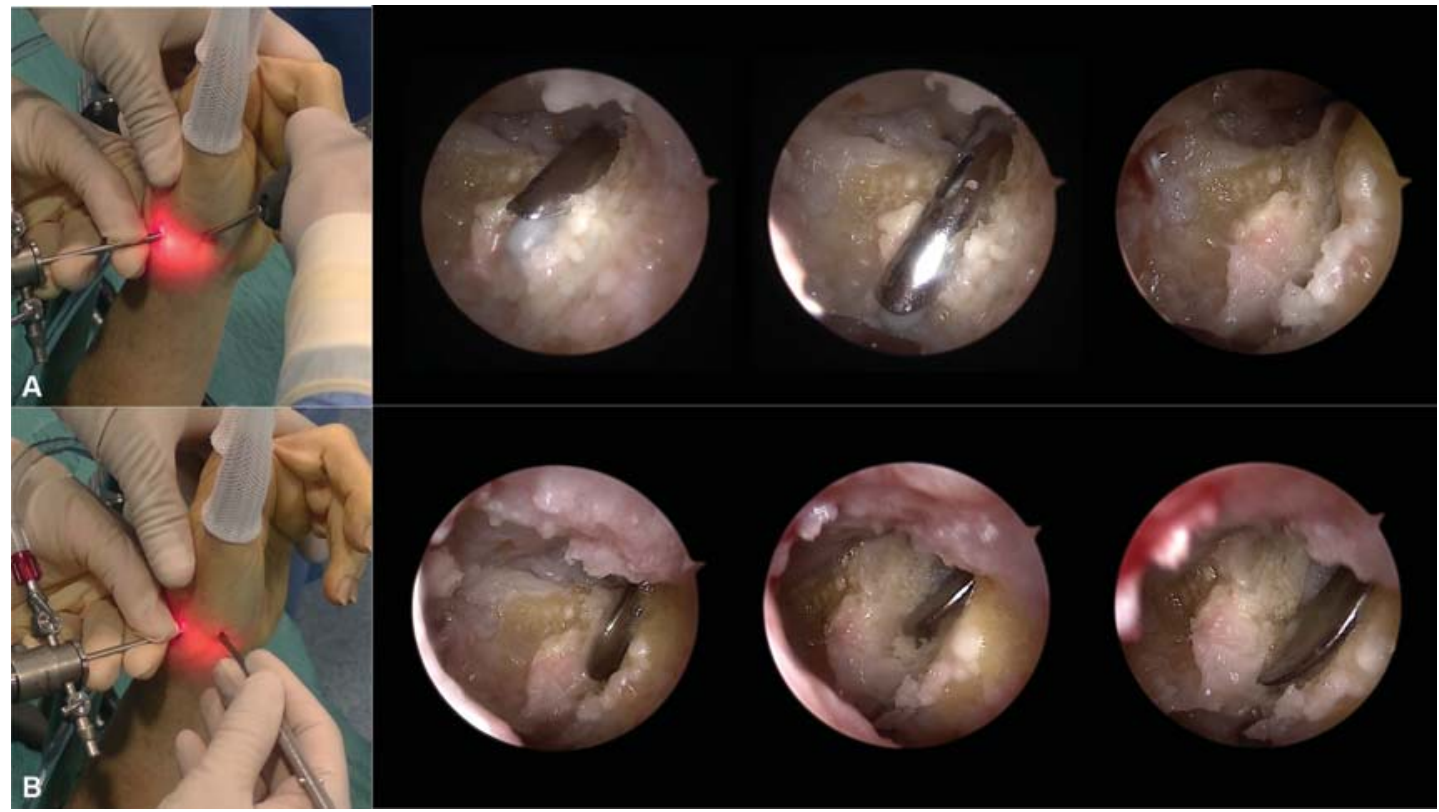

Fig. 8 (A) In step 2, zones 2 and 3 are separated by cutting the bone with the 3-mm burr entering through the thenar portal. (B) The periosteal elevator is also useful to detach one zone from the other.

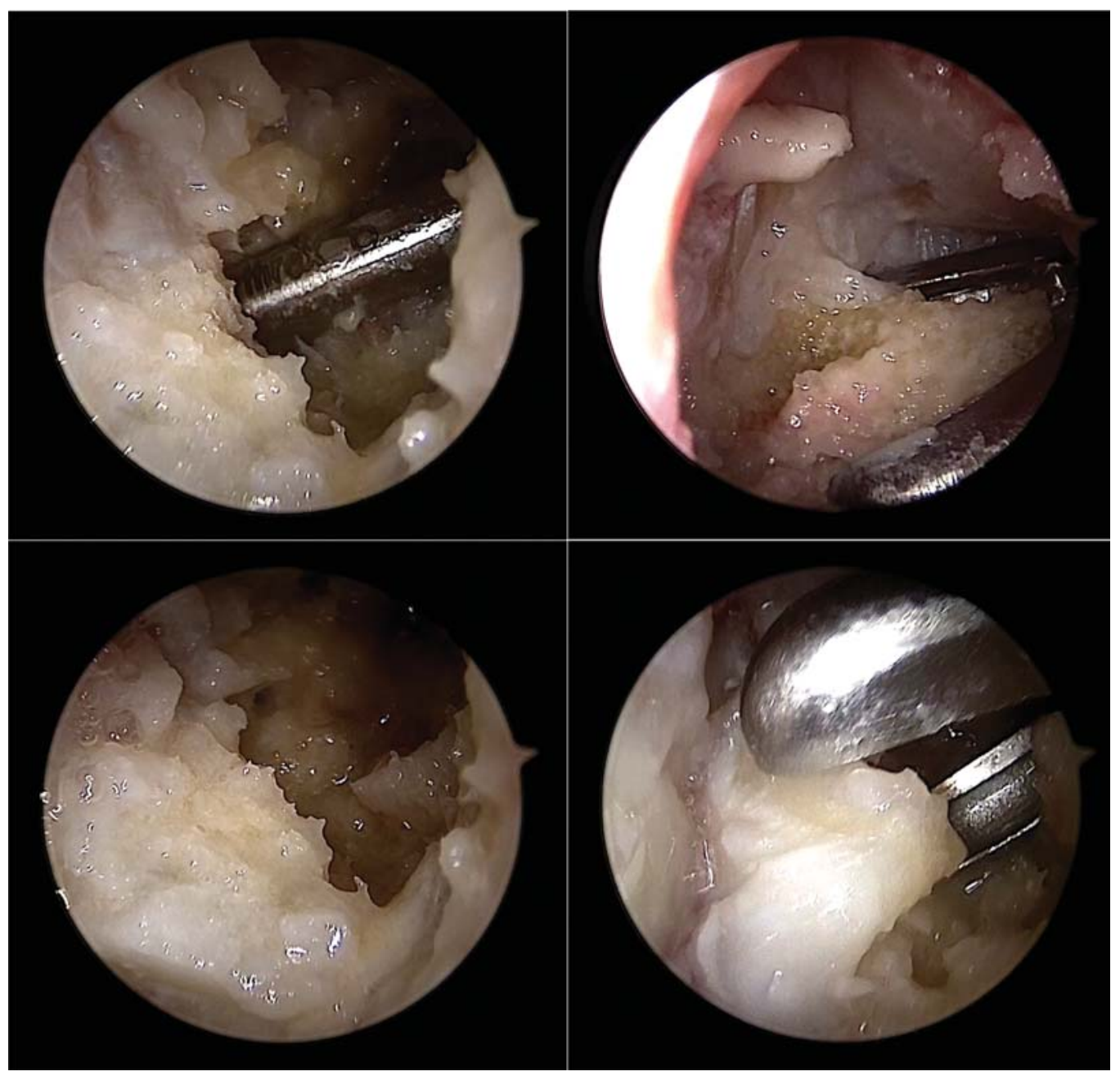

Fig. 9 Zone 2 (half of the volar bone covering one-third of the radial side of the trapezium, as well as the cartilage and subchondral bone over the scaphoid) is removed using the burr, periosteal elevator, and rongeur. 


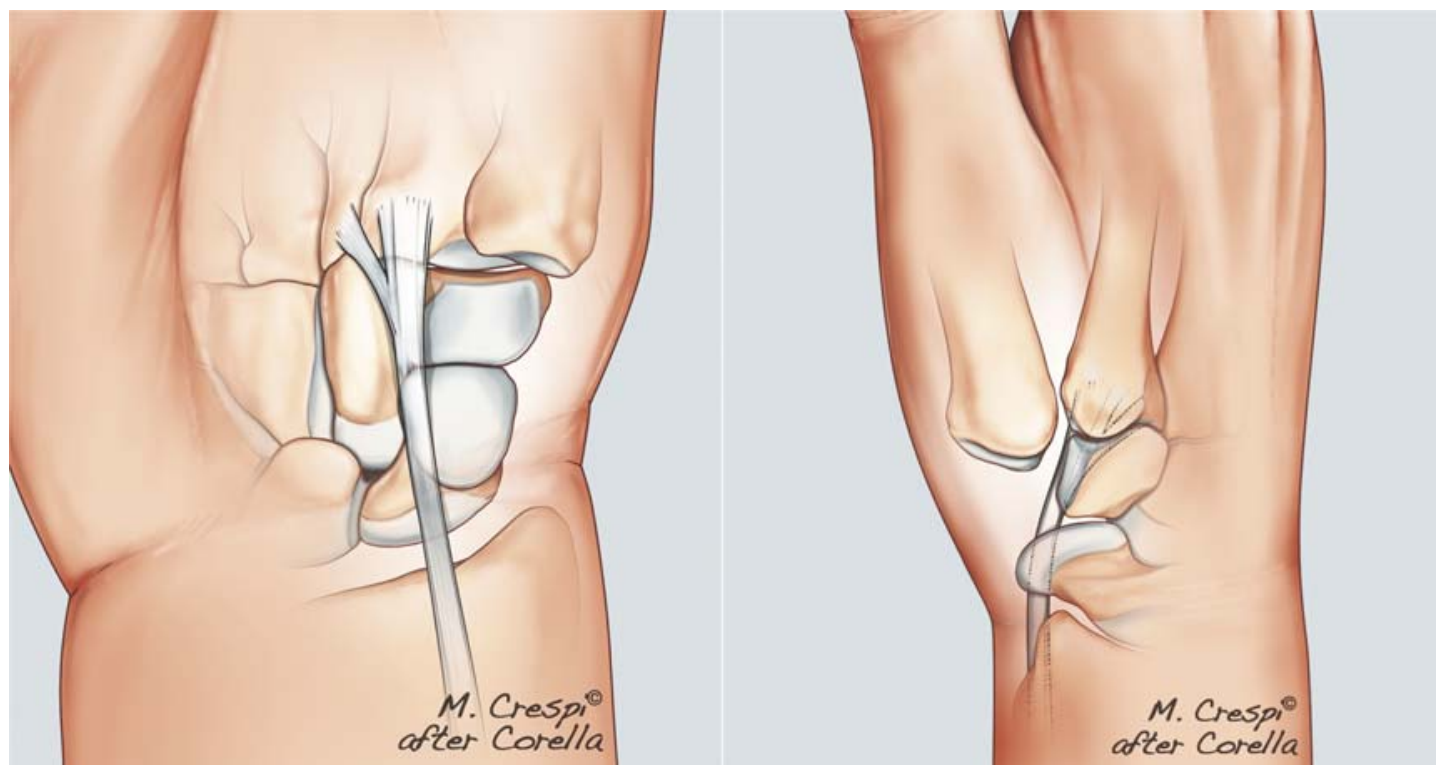

Fig. 10 The flexor carpi radialis tendon is located in the corner between the scaphoid and trapezoid, making the bone of the trapezium covering it zone 2 .
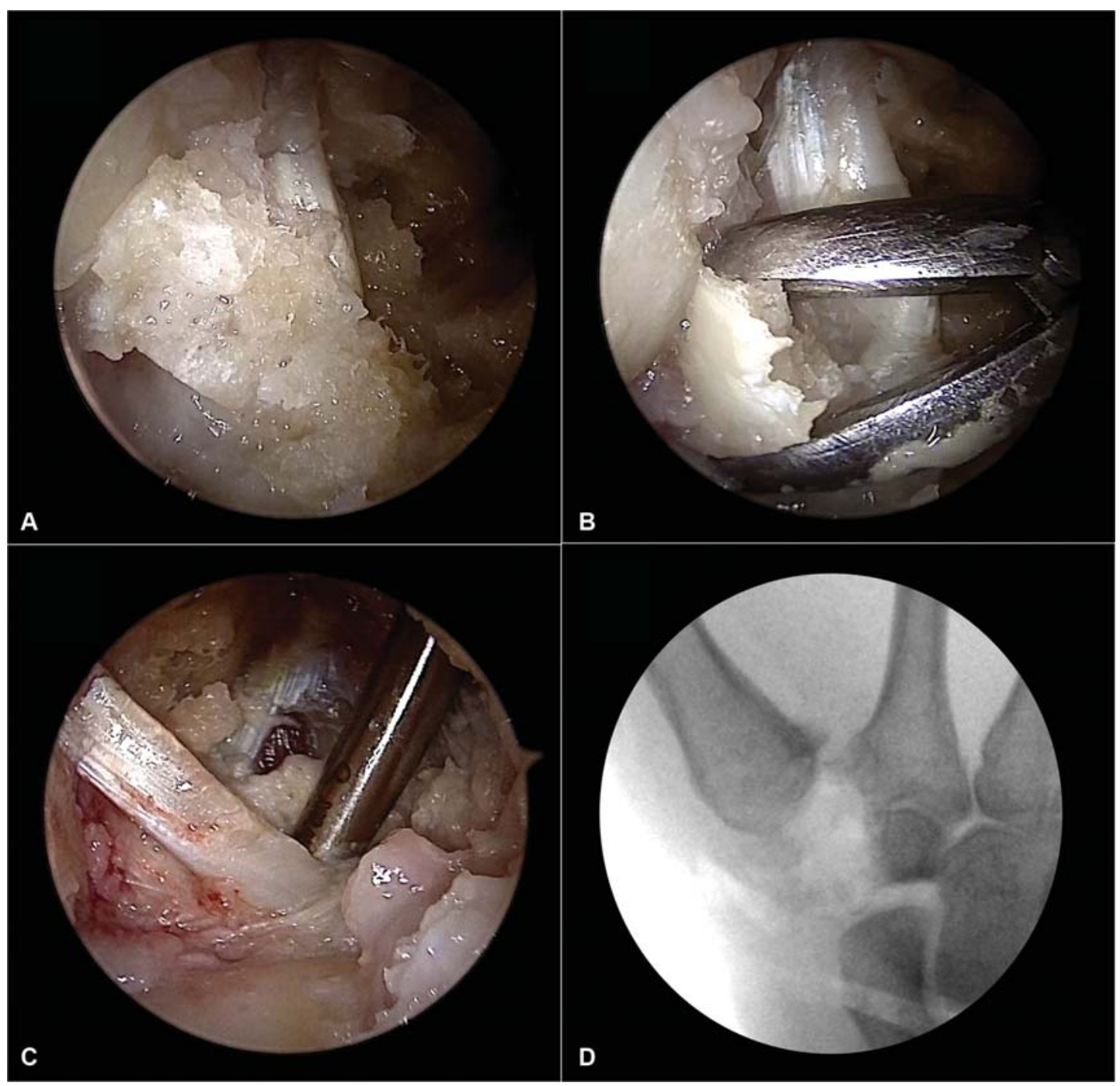

Fig. 11 (A) The flexor carpi radialis is immediately in front of the arthroscope, which is why it is easier to perform the resection in this step. (B,C) The bone surrounding the flexor carpi radialis is removed using the burr, periosteal elevator, and rongeur. (C) When step 2 is finished, only the bone of zone 3 is seen in the X-ray, and often with difficulty, but there is still bone remaining to be resected. 


\section{Step 2: Trapezium volar Radial Portion (Zone 2) Resection}

This step begins by cutting and bisecting the radial portion (zones 2 and 3 ) followed by the resection of zone 2 ( - Fig. 7 ).

In this step, the arthroscope should be moved from the thenar portal to the $1 \mathrm{U}$ portal. The arthroscope will rest over the proximal cartilage of the trapezium covering the scaphoid. First, the 3-mm burr is introduced through the thenar portal and used to separate zone 2 from zone 3 . The periosteal elevator is also useful to this end (-Fig. 8).

As before, using the burr, the periosteal elevator, and the rongeur, all the bones of the zone 2 (half of the volar bone on the one-third radial side of the trapezium, as well as the cartilage and subchondral bone over the scaphoid) are

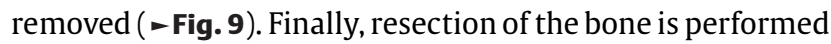
around the FCR tendon, which is located in the corner between the scaphoid and trapezoid (-Fig. 10) and is, therefore, covered by the bone of zone 2 . As the arthroscope is immediately in front of the tendon, the bone can more easily be moved around it during this step (-Fig. 11).

\section{Step 3: Trapezium Dorsal Radial Portion (Zone 3) Resection}

In this step, the arthroscope is again located in the thenar portal, and the bone of zone 3 is removed ( $\mathbf{- F i g . 1 2}$ ). This zone is one of the most difficult portions of the trapezium to remove because it is between the two portals; thus, a direct view cannot be obtained.

With the burr and the shaver in the $1 \mathrm{U}$ portal, the inner portion of the bone is resected. Next, using the periosteal elevator and rongeur, the bone is detached from the capsule. This detachment is commonly performed without a direct view (-Fig. 13).

Finally, the joint of the second metacarpal, the trapezoid, the scaphoid, and the FCR are checked arthroscopically to

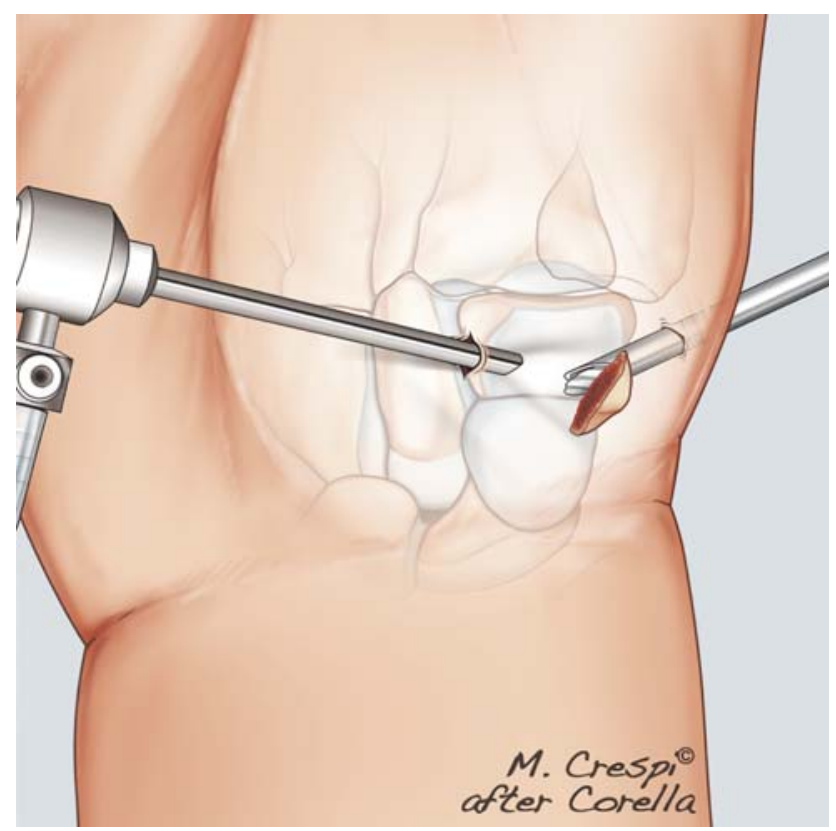

Fig. 12 Step 3. The arthroscope is moved again in the thenar portal, and the bone of zone 3 is removed. ensure complete resection. The resection is also checked with the help of the fluoroscope (-Fig. 14).

\section{Proximal Resection of the Trapezoid}

If the patient shows degenerative changes in the STT joint, resection of the proximal portion of the trapezoid can be performed arthroscopically. This resection is performed with the scope in the thenar portal and the burr in the $1 \mathrm{U}$ portal (-Fig. 15).

\section{Colocation of the Suture Button}

There is no need to remove the patient's hand from the traction tower to place the suture button. In fact, it is easier to

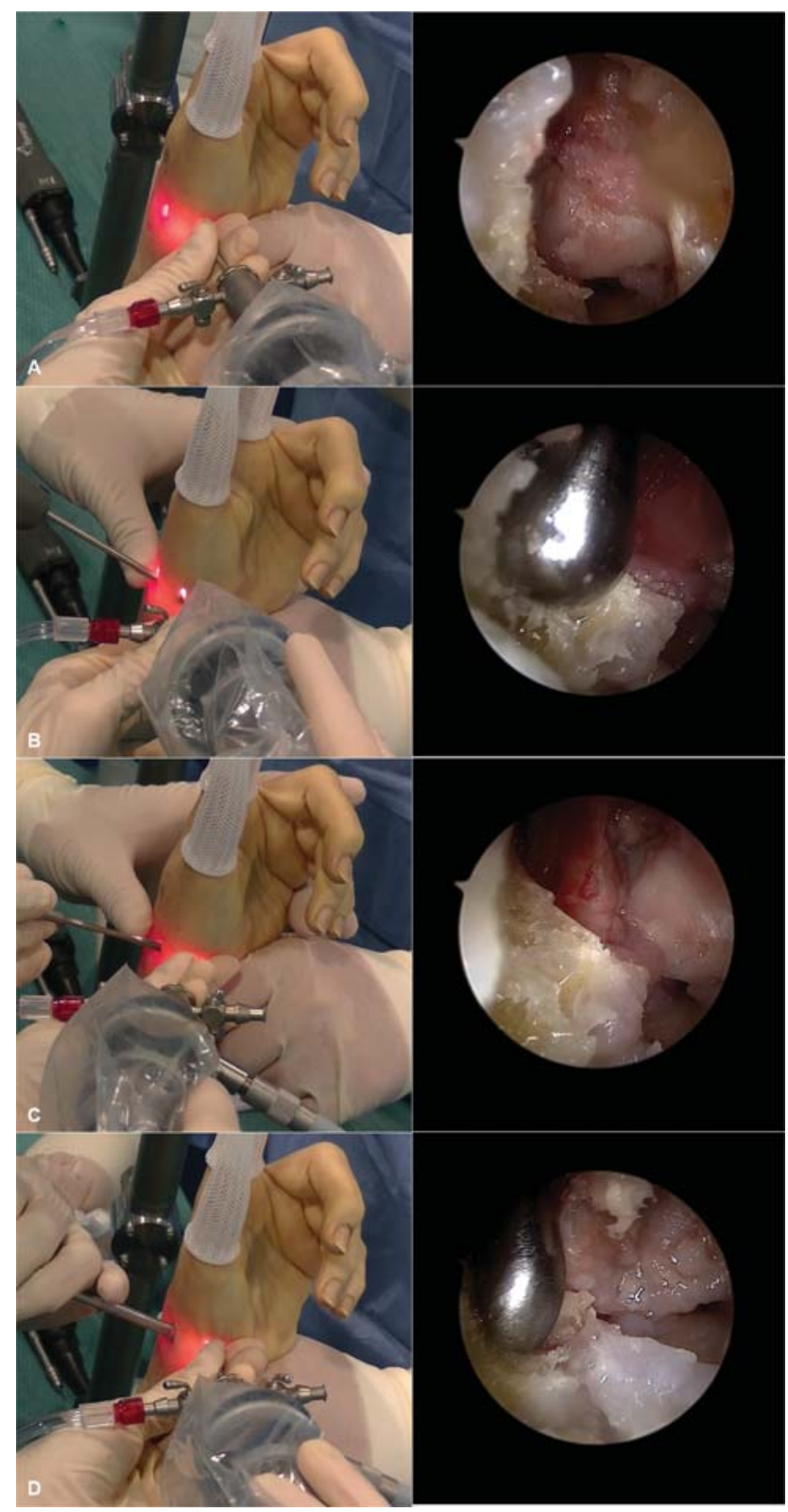

Fig. 13 (A) The bone of zone 3 is one of the most difficult portions of the trapezium to remove because it is between the two portals and a direct view cannot be obtained. The bone is always in the dorsal side of the image. (B) With the burr or the shaver in the $1 \mathrm{U}$ portal, the inner portion of the bone is resected. (C,D) Using the periosteal elevator and rongeur, the bone is then detached from the capsule. 


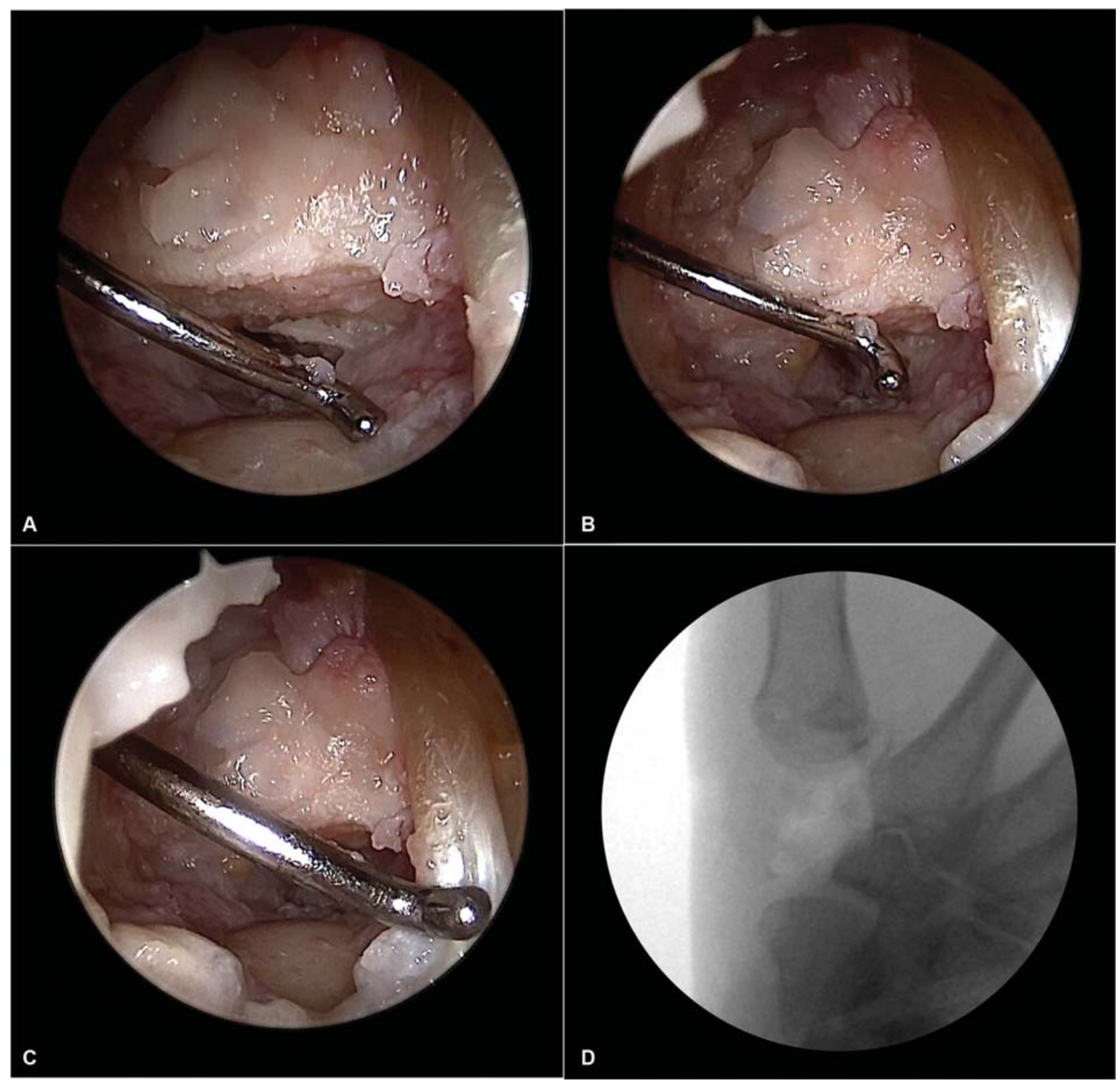

Fig. 14 (A-C) The joint of the second metacarpal, the trapezoid, the scaphoid, and the flexor carpi radialis are checked arthroscopically to ensure complete resection. (D) The resection is also checked using a fluoroscope to ensure that no bone remains.

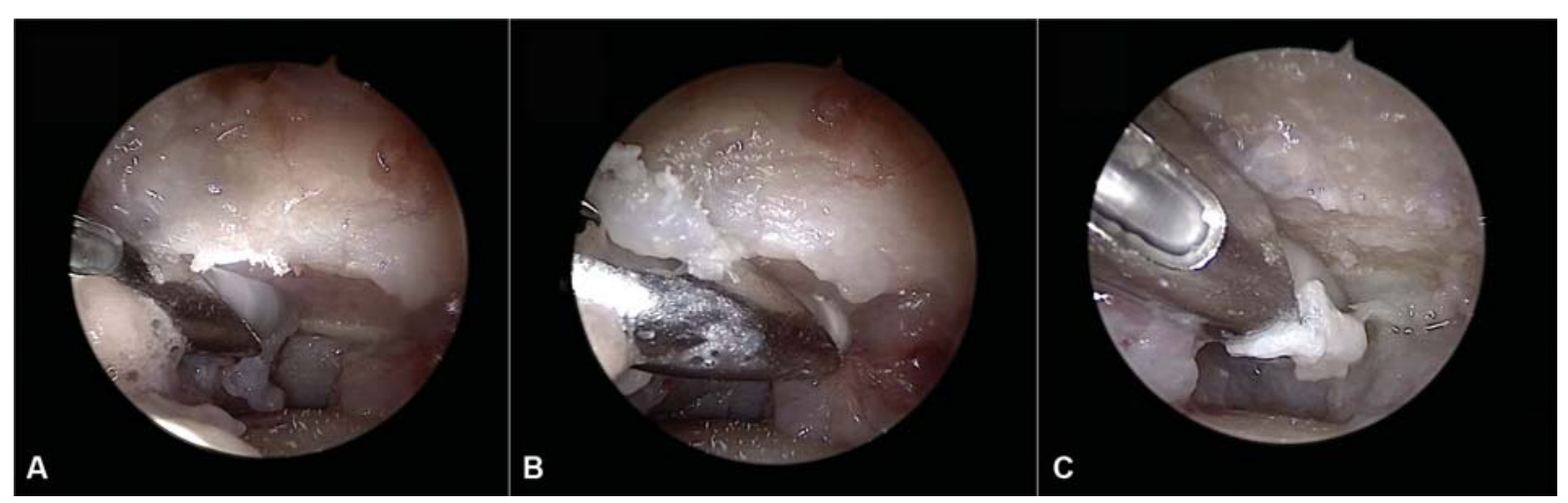

Fig. 15 If there are degenerative changes in the scaphotrapezoid joint, the resection of the proximal portion of the trapezoid is performed with the scope in the thenar portal and the burr in the $1 \mathrm{U}$ portal. 


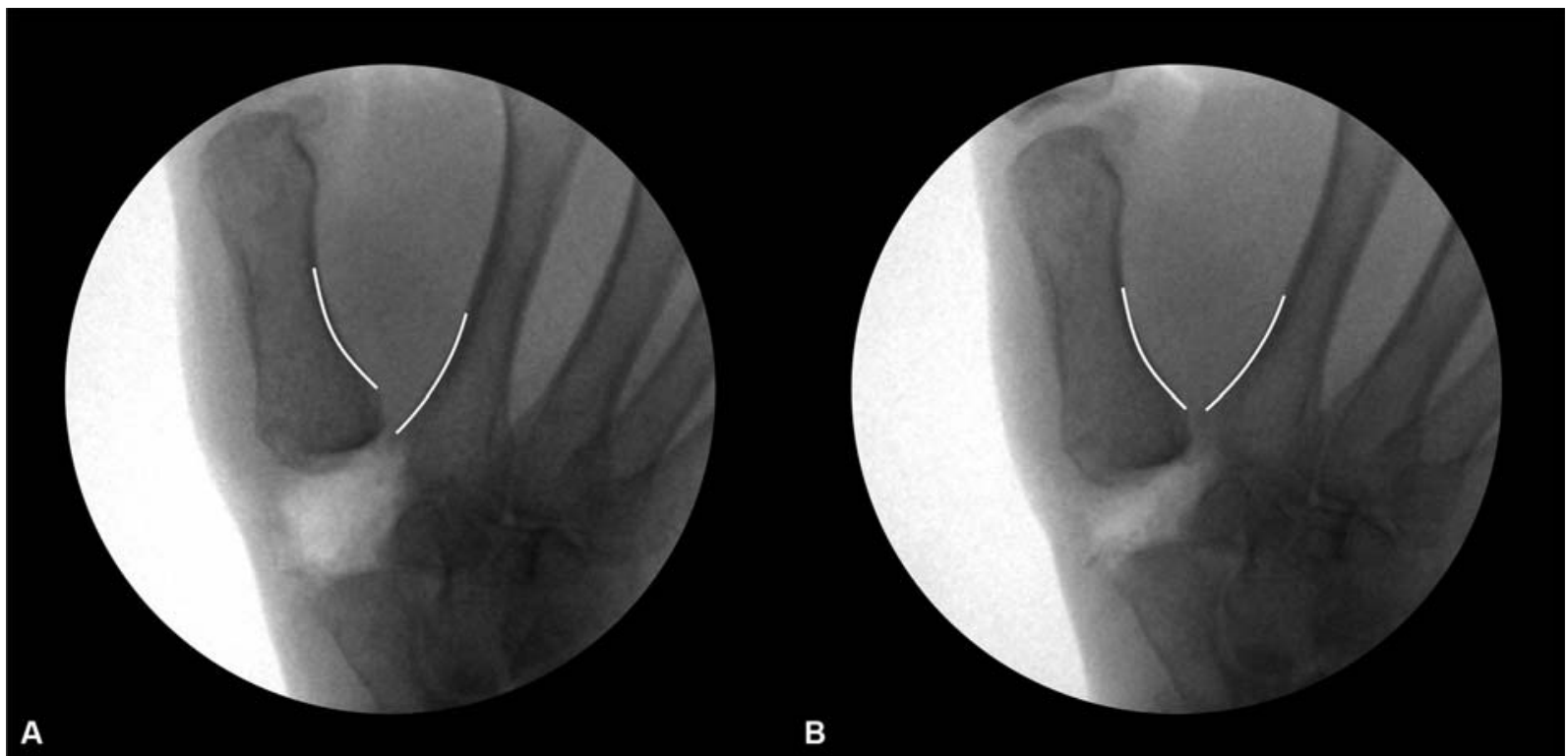

Fig. 16 The height of the first metacarpal is adjusted by removing some traction of the finger trap until the X-ray shows a perfect position, that is, when a " $\mathrm{V}$ " is seen between the first and the second metacarpal bones.

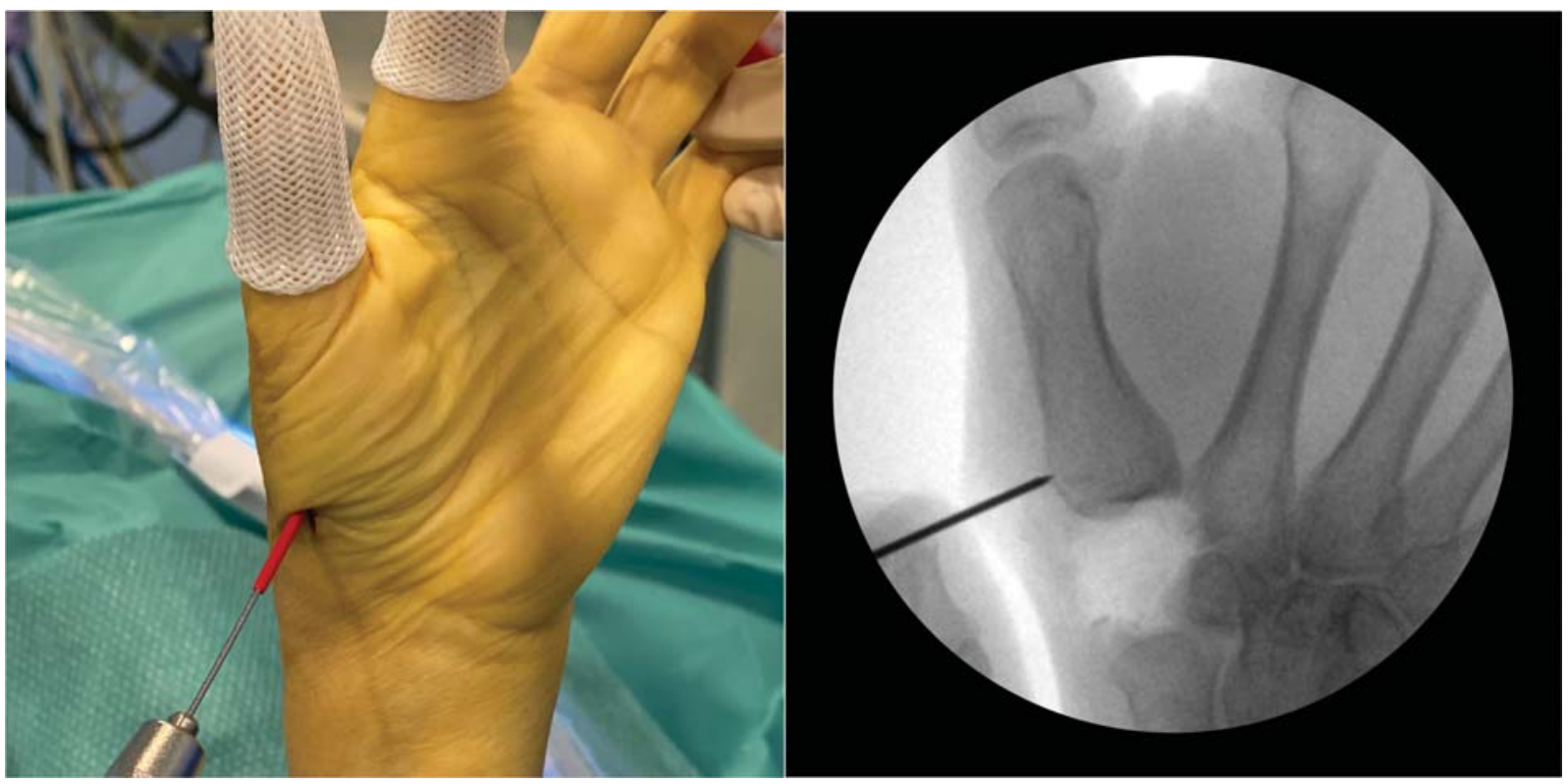

Fig. 17 The volar entry point is easily located through the thenar portal, sliding the tip of the guide wire slightly distal $(1 \mathrm{~cm}$ from the articular surface) and dorsal.

achieve a correct implant position with the hand in the same position as in previous steps.

In our opinion, there are two aspects of correct position: (1) correct height, that is, the base of the first metacarpal bone should make a " $\mathrm{V}$ " with the base of the second; (2) the thumb should not be fixed pronated but supinated because a pronated position will make extension and abduction of the thumb more difficult.

Maintaining the hand suspended in the traction tower makes these two goals easier to achieve than when the hand rests on a table. First, the height of the first metacarpal is adjusted by removing some traction of the finger trap until the X-ray shows perfect position, that is, when a " $\mathrm{V}$ " is seen between the first

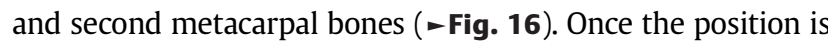

correct, no further adjustment is necessary during the introduction of the SBS. Second, to avoid pronation of the thumb, the entry point should be volar to the first extensor tendon compartment. This way, when the thread is tensioned, the metacarpal will be supinated. This volar entry point is easily located through the thenar portal, sliding the tip of the guidewire slightly distal ( $1 \mathrm{~cm}$ from the articular surface) and dorsal (-Fig. 17). Furthermore, as traction is maintained from the first and second fingers, the thumb and first metacarpal bone are already supinated. If stabilization is performed with the hand resting over a hand table, as is commonly performed in open surgery, the comfortable position is with the thumb in opposition so that it is pronated. However, this makes extension and retropulsion difficult after surgery (- Fig. 18). 


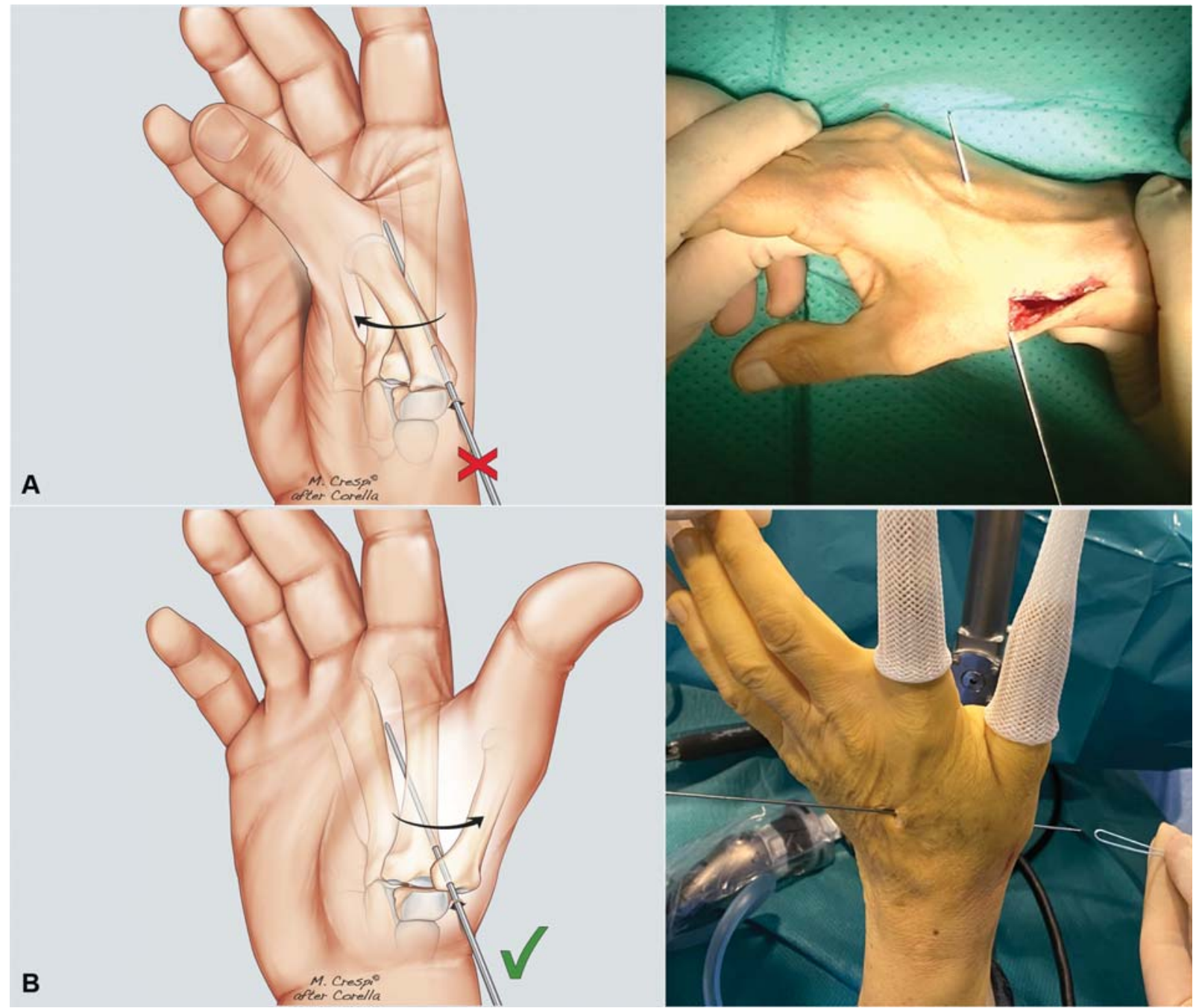

Fig. 18 (A) If stabilization is performed with the hand resting over a hand table, as is commonly done in open surgery, the comfortable position is with the thumb in opposition so that it is pronated. However, this extension and retropulsion are difficult after surgery. (B) Maintaining the hand suspended in the traction tower makes correct positioning of the stabilization easier. The entry point is volar to the first extensor tendon compartment, which is located through the thenar portal. The thumb and the first metacarpal bone are already supinated.

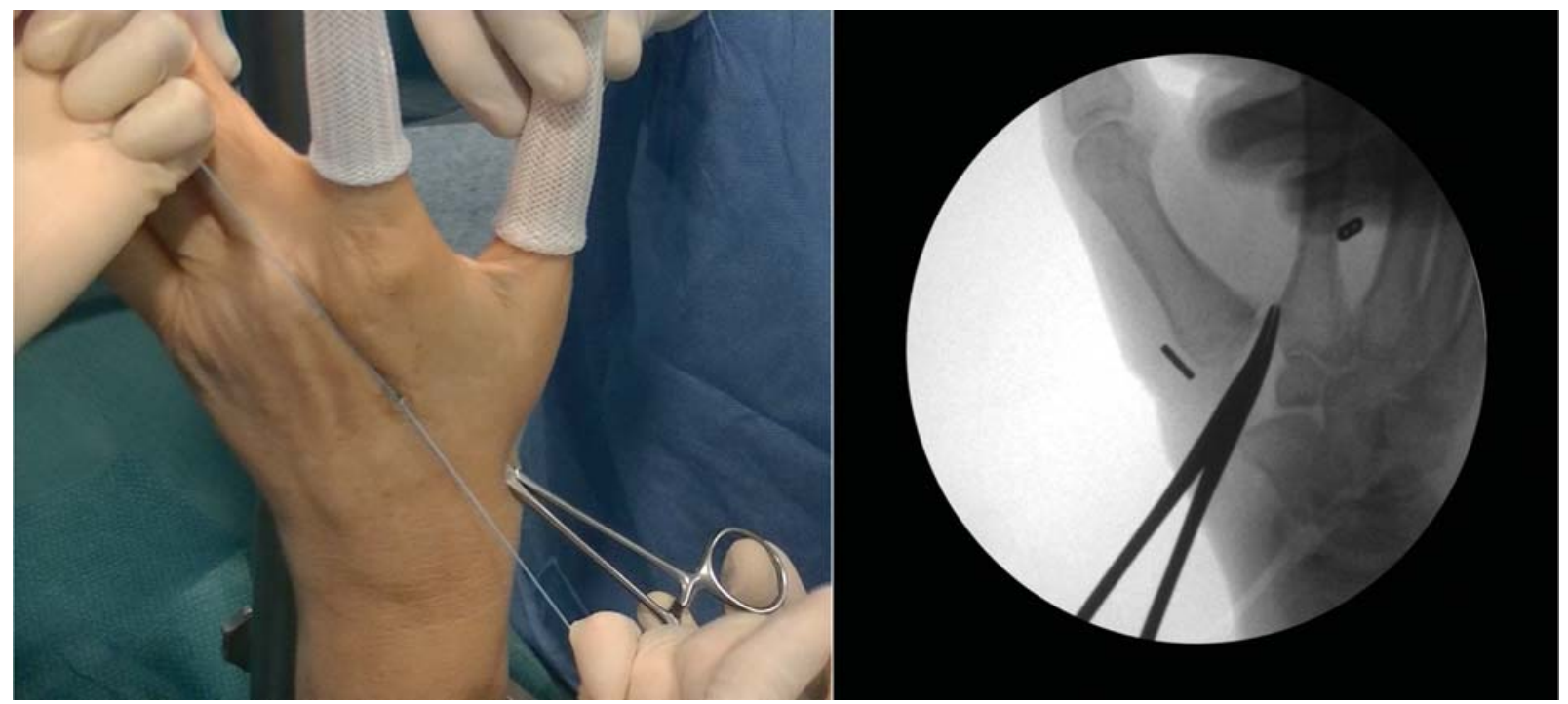

Fig. 19 To avoid impingement between the first and second metacarpal bones, a mosquito is introduced through the $1 \mathrm{U}$ portal and placed between the bones. This way, even though the knot is strongly fixed, there will be always space between the bones. 
Fixation can be performed using either a guide or free hand, and the method depends on the implant. We have always used the Mini TightRope, but the MicroLink has recently been commercialized.

When the implant has been positioned, a knot is made, avoiding impingement between the first and second metacarpal bones. To this end, it is useful to introduce a mosquito through the $1 \mathrm{U}$ portal and place it between the bones. In doing so, even though the knot is strongly fixed, a space always remains between the bones ( $\mathbf{- F i g . 1 9 )}$.

Finally, traction is released and the maintenance of height is checked.

The portals and the wound over the second metacarpal bone are closed using 5/0 monofilament suture, and the hand is place in a cast, with the thumb in abduction.

\section{Postoperative Management}

The cast is maintained for 2 to 3 weeks, at which point rehabilitation begins to regain motion and pinch strength. Specifically, the first interosseous muscle and opponent muscle are boosted. ${ }^{42}$

\section{Conflict of Interest}

None declared.

\section{References}

1 Cobb TK, Walden AL, Cao Y. Long-term outcome of arthroscopic resection arthroplasty with or without interposition for thumb basal joint arthritis. J Hand Surg Am 2015;40(09):1844-1851

2 Badia A. Arthroscopy of the trapeziometacarpal and metacarpophalangeal joints. J Hand Surg Am 2007;32(05):707-724

3 Pegoli L, Parolo C, Ogawa T, Toh S, Pajardi G. Arthroscopic evaluation and treatment by tendon interpositional arthroplasty of first carpometacarpal joint arthritis. Hand Surg 2007;12(01):35-39

4 Eaton RG, Glickel SZ. Trapeziometacarpal osteoarthritis. Staging as a rationale for treatment. Hand Clin 1987;3(04):455-471

5 Desmoineaux P, Delaroche C, Beaufils P. Partial arthroscopic trapeziectomy with ligament reconstruction to treat primary thumb basal joint osteoarthritis. Orthop Traumatol Surg Res 2012;98(07):834-839

6 Hofmeister EP, Leak RS, Culp RW, Osterman AL. Arthroscopic hemitrapeziectomy for first carpometacarpal arthritis: results at 7-year follow-up. Hand (N Y) 2009;4(01):24-28

7 Edwards SG, Ramsey PN. Prospective outcomes of stage III thumb carpometacarpal arthritis treated with arthroscopic hemitrapeziectomy and thermal capsular modification without interposition. J Hand Surg Am 2010;35(04):566-571

8 Cox CA, Zlotolow DA, Yao J. Suture button suspensionplasty after arthroscopic hemitrapeziectomy for treatment of thumb carpometacarpal arthritis. Arthroscopy 2010;26(10): 1395-1403

9 Adams JE, Steinmann SP, Culp RW. Bone-preserving arthroscopic options for treatment of thumb basilar joint arthritis. Hand Clin 2011;27(03):355-359

10 Abzug JM, Osterman AL. Arthroscopic hemiresection for stage IIIII trapeziometacarpal osteoarthritis. Hand Clin 2011;27(03): 347-354

11 Logli AL, Twu J, Bear BJ, Lindquist JR, Schoenfeldt TL, Korcek KJ Arthroscopic partial trapeziectomy with soft tissue interposition for symptomatic trapeziometacarpal arthritis: 6-month and 5year minimum follow-up. J Hand Surg Am 2018;43(04):384. e1-384.e7
12 Earp BE, Leung AC, Blazar PE, Simmons BP. Arthroscopic hemitrapeziectomy with tendon interposition for arthritis at the first carpometacarpal joint. Tech Hand Up Extrem Surg 2008;12(01): 38-42

13 Menon J. Arthroscopic management of trapeziometacarpal joint arthritis of the thumb. Arthroscopy 1996;12(05):581-587

14 Özçelik İB, Uğurlar M, Sarı A. Arthroscopic hemitrapeziectomy and suture button suspensionplasty in the treatment of first carpometacarpal joint Eaton-Littler stage 2-3 arthrosis. J Wrist Surg 2019;8(02):132-138

15 Chuang MY, Huang CH, Lu YC, Shih JT. Arthroscopic partial trapeziectomy and tendon interposition for thumb carpometacarpal arthritis. J Orthop Surg Res 2015;10(01):184

16 Wong CW, Ho PC. Arthroscopic management of thumb carpometacarpal joint arthritis. Hand Clin 2017;33(04):795-812

17 Daroda S, Menvielle F, Cosentino R, Pereira P. Arthroscopic total trapeziectomy. Tech Hand Up Extrem Surg 2010;14(04): 259-262

18 Landes G, Gaspar MP, Goljan P, Jacoby SM, Bachoura A, Culp RW. Arthroscopic trapeziectomy with suture button suspensionplasty: a retrospective review of 153 cases. Hand (N Y) 2016;11 (02):232-237

19 Kuhns CA, Emerson ET, Meals RA. Hematoma and distraction arthroplasty for thumb basal joint osteoarthritis: a prospective, single-surgeon study including outcomes measures. J Hand Surg Am 2003;28(03):381-389

20 Amadio PC, Millender LH, Smith RJ. Silicone spacer or tendon spacer for trapezium resection arthroplasty-comparison of results. J Hand Surg Am 1982;7(03):237-244

21 Burton RI, Pellegrini VD Jr. Surgical management of basal joint arthritis of the thumb. Part II. Ligament reconstruction with tendon interposition arthroplasty. J Hand Surg Am 1986;11 (03):324-332

22 Yao J. Suture-button suspensionplasty for the treatment of thumb carpometacarpal joint arthritis. Hand Clin 2012;28(04):579-585

23 Friebel TR, Walbeehm ET, Kleinrensink GJ, Ray S, Zuidam JM. An anatomical study on the effectiveness of Arthrex Mini TightRope ${ }^{\circledR}$ ligament reconstruction in an unstable trapeziometacarpal joint. Arch Orthop Trauma Surg 2018;138(07):1029-1033

24 Naram A, Lyons K, Rothkopf DM, et al. Increased complications in trapeziectomy with ligament reconstruction and tendon interposition compared with trapeziectomy alone. Hand (N Y) 2016;11 (01):78-82

25 Wajon A, Vinycomb T, Carr E, Edmunds I, Ada L. WITHDRAWN: Surgery for thumb (trapeziometacarpal joint) osteoarthritis. Cochrane Database Syst Rev 2017;4:CD004631

26 Badia A. Arthroscopic indications and technique for artelon interposition arthroplasty of the thumb trapeziometacarpal joint. Tech Hand Up Extrem Surg 2008;12(04):236-241

27 Adams JE, Merten SM, Steinmann SP. Arthroscopic interposition arthroplasty of the first carpometacarpal joint. J Hand Surg Eur Vol 2007;32(03):268-274

28 Park MJ, Lee AT, Yao J. Treatment of thumb carpometacarpal arthritis with arthroscopic hemitrapeziectomy and interposition arthroplasty. Orthopedics 2012;35(12):e1759-e1764

29 Yao J, Zlotolow DA, Murdock R, Christian M. Suture button compared with K-wire fixation for maintenance of posttrapeziectomy space height in a cadaver model of lateral pinch. J Hand Surg Am 2010;35(12):2061-2065

30 Desai MJ, Brogan DM, Richard MJ, Mithani SK, Leversedge FJ, Ruch DS. Biomechanical comparison of suture-button suspensionplasty and LRTI for basilar thumb arthritis. Hand (N Y) 2016;11 (04):438-443

31 Hooke AW, Parry JA, Kakar S. Mini TightRope fixation versus ligament reconstruction - tendon interposition for maintenance of post-trapeziectomy space height: a biomechanical study. J Hand Surg Am 2016;41(03):399-403 
32 Yao J, Song Y. Suture-button suspensionplasty for thumb carpometacarpal arthritis: a minimum 2-year follow-up. J Hand Surg Am 2013;38(06):1161-1165

33 Khalid M, Jones ML. Index metacarpal fracture after tightrope suspension following trapeziectomy: case report. J Hand Surg Am 2012;37(03):418-422

34 Yao J, Cheah AEJ. Mean 5-year follow-up for suture button suspensionplasty in the treatment of thumb carpometacarpal joint osteoarthritis. J Hand Surg Am 2017;42(07):569.e1-569. e11

35 Graham JG, Rivlin M, Abboudi J, Lutsky K, Beredjiklian PK. Delayed, atraumatic index metacarpal fracture after trapeziectomy and suture-button suspensionplasty for thumb carpometacarpal osteoarthritis: a report of three cases. J Hand Surg Am 2019;44(04):344.e1-344.e5

36 Roman PB, Linnell JD, Moore JB. Trapeziectomy arthroplasty with suture suspension: short- to medium-term outcomes from a single-surgeon experience. J Hand Surg Am 2016;41(01):34-39. e1
37 Daroda S. Artrosis carpometacarpiana del pulgar: trapecectomía simple viseoasistida. Rev Argentina Ortop y Traumatol 2003; 68:267-277

38 del Piñal F, García-Bernal FJ, Pisani D, Regalado J, Ayala H, Studer A. Dry arthroscopy of the wrist: surgical technique. J Hand Surg Am 2007;32(01):119-123

39 Eaton RG, Lane LB, Littler JW, Keyser JJ. Ligament reconstruction for the painful thumb carpometacarpal joint: a long-term assessment. J Hand Surg Am 1984;9(05):692-699

40 Walsh EF, Akelman E, Fleming BC, Dasilva MF. Arthroscopy: a topographic, anatomic study of the thenar portal. J Hand Surg Am 2005;30:373-379

41 Pan YW, Hung LK. The safety of the thenar portal: an anatomical study of the thumb carpometacarpal arthroscopy. J Wrist Surg 2017;6(02):152-157

42 Mobargha N, Esplugas M, Garcia-Elias M, Lluch A, Megerle K, Hagert $\mathrm{E}$. The effect of individual isometric muscle loading on the alignment of the base of the thumb metacarpal: a cadaveric study. J Hand Surg Eur Vol 2016;41(04):374-379 